\title{
HYBRID TRANSMISSIONS FOR THE OPTIMISATION OF THE EFFICIENCY OF INTERNAL COMBUSTION ENGINES
}

\author{
F. CONCLI \& C. NEZZI \\ Free University of Bolzano/Bozen, Faculty of Science and Technology, Bolzano, Italy
}

\begin{abstract}
Eco-friendly technologies, such as renewable energies, represent the future. The field of automotive is moving in this direction as well, especially with the introduction of hybridisation to reduce fuel consumptions. This paper presents a methodology aimed to optimise the internal combustion engine (ICE) efficiency with a new concept of continuously variable transmission (CVT). The starting point of the research is the investigation of the fuel consumption of a representative powertrain in different driving cycles; numerical simulations provides detailed information about fuel efficiency in the case of real and ideal ICE working conditions (manual transmission vs. ideal CVT). End scope of the work is to explore the possible optimisation of the ICE consumptions, aiming at the achievement of a reduction of the pollutant emissions and an increase of its efficiency by means of innovative system architectures. Keywords: CVT, driving cycle, efficiency, fuel consumption, hybrid transmissions, ICE, optimisation.
\end{abstract}

\section{INTRODUCTION}

Nowadays the issue of energy consumption is strongly addressed by the whole human race, since its direct consequences affect our everyday lives.

On one hand, the tendency to consume growing quantities of energy and resources constitutes an alarming signal. Moreover, technological and social progresses are strictly related to resource availability. Their exploitation is becoming tremendously massive, especially looking at recent years if compared to the past century. On the other hand, a deep awareness of these difficulties is currently spreading among all the countries: the countertrend based on reducing the carbon footprint starts obtaining a great favour. New eco-friendly technologies were developed with the aim of reducing waste and human impact on the surrounding environment; for instance, the growth of renewable energies employed in a more sustainable management of resources may be seen as a positive evidence for the future.

These forward-looking trends have a considerable effect also on the automotive field, whose major concern is the limitation in the usage of fossil fuels, considering that their accessibility could become critical in a mid-term future. Moreover, almost all types of internal combustion engines (ICEs) produce a significant quantity of exhaust gases, that represent one of the main responsible for the environmental pollution of the planet. Consequently, seeking after alternative solutions to traditional ICE-driven systems is getting more and more foothold in the field of scientific research. Recent technologies have brought to the development of hybrid-electric- (HEV) and pure electric-vehicles (EV), which exploit partially or totally an e-Motor propulsion [1]. One of the great advantages of these motor types is the capability to significantly reduce pollutant emissions, hence they are widely known as green technologies.

Hybridisation is a growing trend of the last years that originates from Japan; the general diffusion of hybrid vehicles certainly derives from several environmental problems. Moreover, the exploitation of the high efficiency of electric motors has still a great appeal. The basic concept of HEV is to combine an ICE with the propulsion given by an electric source. The e-Motor performs its proper functionality when the ICE reaches the points of lowest efficiency, such as cold starts, hard braking and overtaking: indeed, these are the moments of 
highest fuel consumption and gas emission. The electric system has normally the capability to recover the kinetic energy that would be otherwise lost, for example, during the braking phases, storing it a re-use it afterwards. On one side, HEV are extremely energy efficient if used throughout city traffic promoting at the same time a reduction of the gas emissions. On the other side, they show also peculiar problems. First, HEV are equipped with a storage system, normally high voltage lithium batteries [2], needed to store the recovered energy during the driving cycle and subsequently to power the e-Motor. Storage devices are very heavy [3], and this partially reduces the possible fuel savings. Moreover, the life and prices of such devices have not convinced buyers yet. Second, the most common type of transmission system used in HEV is the CVT [4][5]. The remarkable advantage of CVTs is the infinite number of gear ratios exploitable during the driving cycle, limited by the number of gears in a manual transmission (MT). CVTs allow to keep the rotational speed of the ICE constant releasing the motor speed from the one of the wheels. Although the choice of a CVT with respect to a MT is driven by the possibility to induce the motor to operate in its ideal operating point, a weighty stumbling block is still to be demolished: efficiency. The power losses in CVTs are not negligible and significantly higher with respect to MT's ones.

\section{OBJECTIVES}

The idea of overcoming the imperfections of MTs (used in traditional vehicles) and CVTs (having low efficiency [6]) lays at the basis of this work. For a given ICE, the transmission could be made by two separated branches with a split of the power flows. The convenience of a system with a MT mounted in parallel to a CVT could be represented by the possibility to have a continuous variable 'global' gear ratio (motor-wheels) ensuring however that the prevalent share of the power is transmitted by the MT, which would guarantee a satisfactory efficiency. Just a small portion of power would flow inside the CVT branch. This is enough to adjust the global gear ratio, notwithstanding lower efficiency outputs. This solution, called Hybrid-CVT (HCVT) could result in a perfect combination of the advantages of both transmissions. In this work the potential benefits of having such an architecture were investigated and compared, in terms of efficiency, with the actual configuration.

\section{MODEL DESCRIPTION}

For simplicity sake, the explanation of the analysis performed will be based on a single driving cycle (New European Driving Cycle - NEDC [7][8]) used as reference. nevertheless, the same approach was used for the analysis of a rich range of driving cycles, to obtain a general overview of how much consumption saving could be achieved with this new concept of transmission, especially in the case of non-homologated cycles.

The most suitable car segment [9] is the so called "small cars" one. An Italian-brand car, the Fiat Grande Punto [10], produced by FCA [11] from 2005 to 2018, powered by a 1.4 16v T-Jet, having $88.25 \mathrm{~kW}$ was selected. This choice was made considering the requirement of studying an urban driving schedule; moreover, the wide diffusion of this car in the whole territory of Italy could arise a significant importance of the practical appeal of this research.

The car has a mass of $P=1,060 \mathrm{~kg}$, a drag coefficient $c_{x}=0.31$ and a frontal surface area equal to $S=1.9 \mathrm{~m}^{2}$. The car was modelled with lumped parameters [12]. Assuming that the vehicle is moving with a constant speed per unit of time on a general path, it is possible to define three different forces acting on the car: the inertial resistant force $R_{i}$, the rolling resistant force $R_{r}$, and the drag resisting one $R_{d}$.

$$
R_{i}[\mathrm{~N}]=P[\mathrm{~kg}] \cdot a\left[\mathrm{~m} / \mathrm{s}^{2}\right]
$$




$$
\begin{gathered}
R_{r}[\mathrm{~N}]=P[\mathrm{~kg}] \cdot g\left[\mathrm{~m} / \mathrm{s}^{2}\right] \cdot f \\
R_{d}[\mathrm{~N}]=1 / 2 \cdot \rho_{a}\left[\mathrm{~kg} / \mathrm{m}^{3}\right] \cdot c_{x} \cdot S\left[\mathrm{~m}^{2}\right] \cdot v[\mathrm{~m} / \mathrm{s}]
\end{gathered}
$$

where $a$ is the acceleration of the vehicle, $g$ the gravitational force, $\rho_{\mathrm{a}}$ is the density of the air and $v$ the vehicle travelling speed. $f$ is the friction coefficient from the literature $(0.01$ for smooth tarmacked pavements).

The sizing of the ICE is made accordingly to the maximum expected power requested by the driver according to

$$
P_{R}[W]=\left(R_{i}+R_{r}+R_{d}\right) \cdot v
$$

\subsection{Mechanical fixed ratio gearbox}

The actual MT of the selected vehicle has 5 gears which reduction ratios are shown in Table 1.

According to the NEDC and the gear ratios of Table 2, the rotational speed of the ICE results as in Figure 2.

The ICE rotational speed $n_{\text {ICE }}$ is calculated based on the wheel radios $r_{\text {wheel }}$ and the gear ratio $\tau$ as
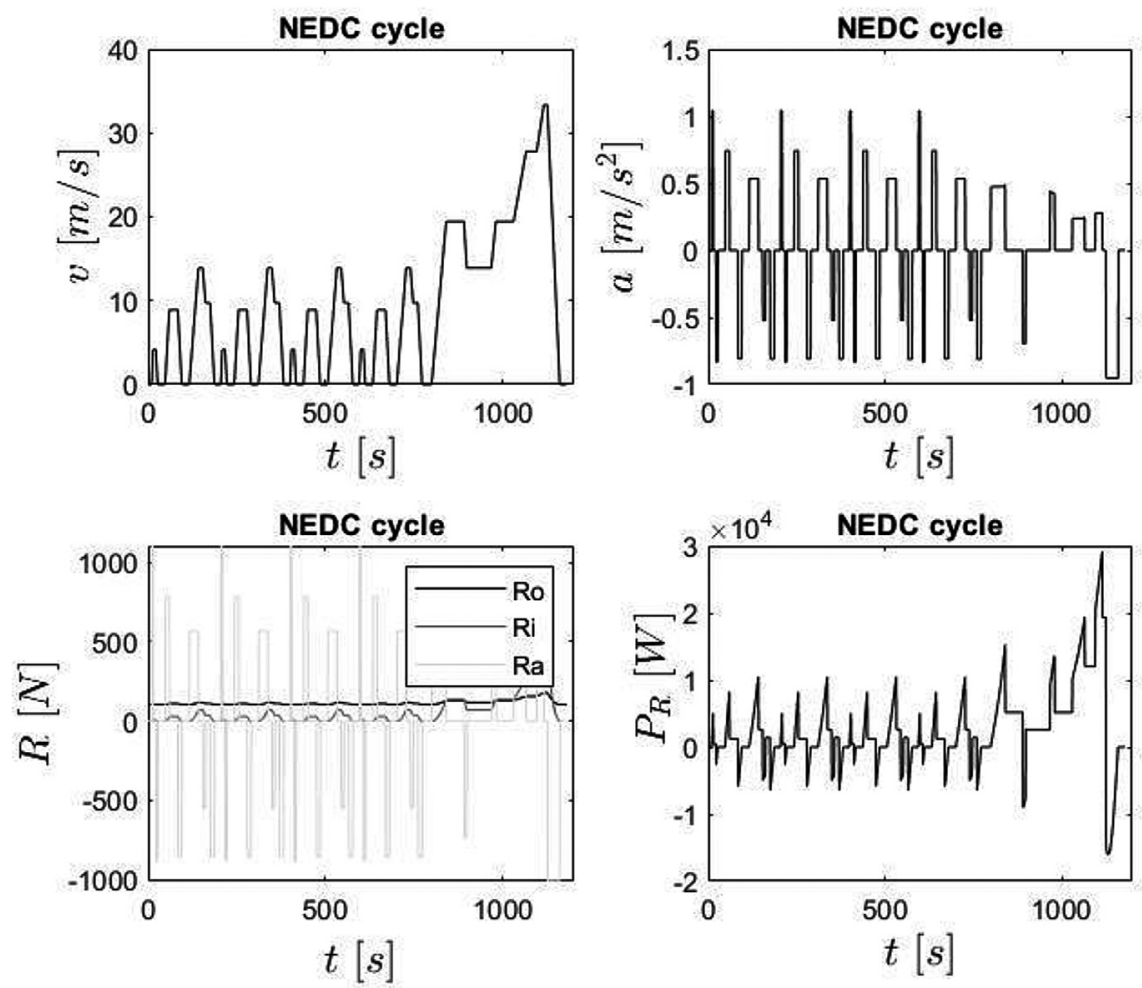

Figure 1: New European Driving Cycle (NEDC): velocities, accelerations, resistant forces and resistant power. 
Table1: Gear ratios of the MT transmission.

\begin{tabular}{llllll}
\hline Gear \# & 1st & 2nd & 3rd & 4th & 5th \\
\hline Ratio & 14.5923 & 8.35445 & 5.3904 & 3.8412 & 3.1282 \\
\hline
\end{tabular}

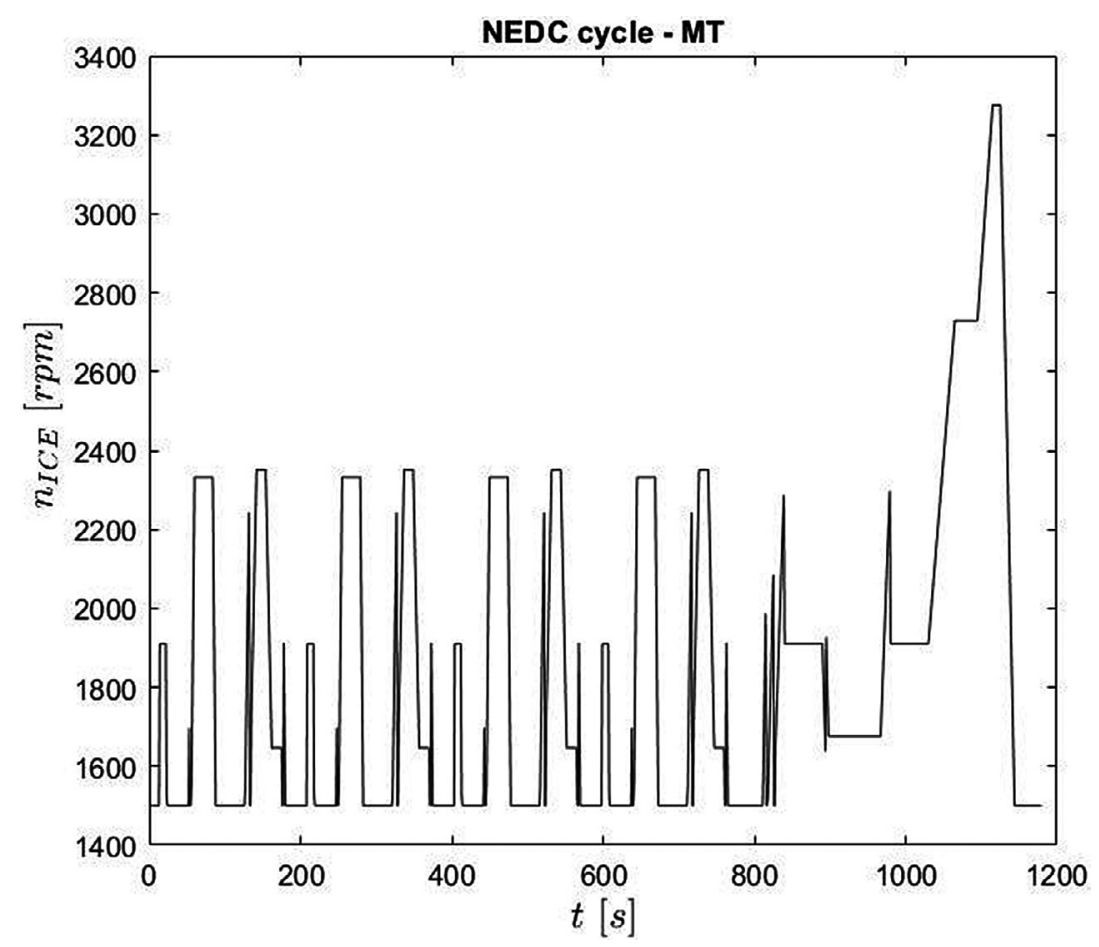

Figure 2: Rotational speed of the ICE when driving on the NEDC cycle.

$$
n_{\mathrm{ICE}}[\mathrm{rpm}]=\frac{v_{\mathrm{NECD}}[\mathrm{m} / \mathrm{s}]}{2 \pi r_{\text {wheel }}[\mathrm{m}] \cdot 60[\mathrm{~min} / \mathrm{s}]} \cdot \tau
$$

The rotational speed of the ICE varies from 1,500 to 6,000 rpm. For completing the NEDC cycle, $n_{\text {ICE }}$ reaches a maximum of 3,300 rpm corresponding to a travelling speed of $120 \mathrm{~km} / \mathrm{h}$ $(33.3 \mathrm{~m} / \mathrm{s})$ in the 5 th gear.

The consumption map of the 1.4 T-Jet ICE is shown in figure 3 Striped lines represent isopower lines.

\section{SIMULATION METHODOLOGY}

\subsection{Manual Transmission}

The fuel consumption must be evaluated on the overall driving cycle (e.g. the NEDC) The instantaneous value can be evaluated knowing the required power $P_{\mathrm{R}}$ and the instantaneous rotational speed of the ICE $n_{\mathrm{ICE}}$. For simplicity's sake, the time discretisation interval was chosen equal to $\Delta t=1 \mathrm{~s}$. 


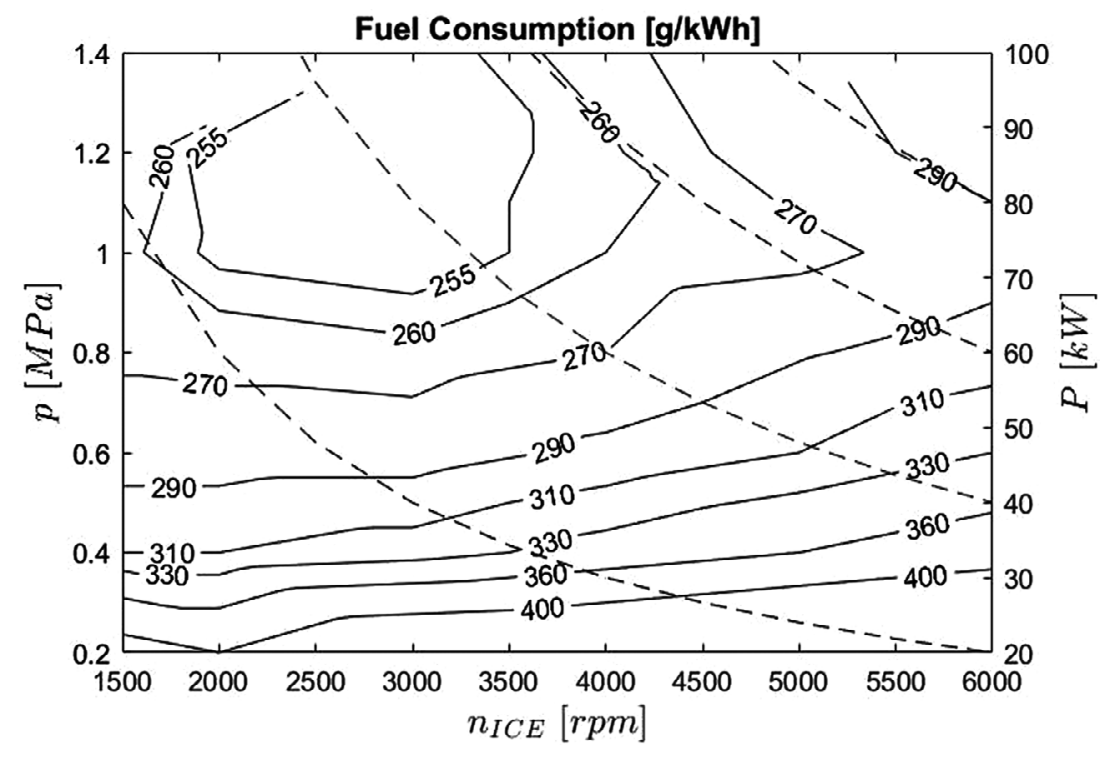

Figure 3: Fuel consumption map.

\subsection{Hybrid-CVT}

The purpose of this research is to investigate whether it could be convenient to split transmission of the power having in addition to the MT a second branch having a variable transmission ratio with the goal of reducing the fuel consumption by exploiting the optimal operating point of the ICE. For most of the time, the potential consumption correspondent to the optimal working point of ICE (in an ideal case were the efficiency of the transmission is neglected) is significantly lower than the on matching the actual working point of ICE (real case). Considering the efficiency of the mechanical transmission is a strong assumption [13]-[18] that should be eliminated in the future.

Laying the instantaneous ICE operating point on a certain iso-power line (Figure 3), an improvement of the efficiency is possible if another point of the same iso-power line shows a lower fuel consumption. As an example, the same power $(P=40 \mathrm{~kW})$ can be provided by the ICE rotating at 6,000 rpm with an Instantaneous Fuel Consumption (IFC) of $360 \mathrm{~g} / \mathrm{kWh}$ or at $3,000 \mathrm{rpm}$ with an IFC below $250 \mathrm{~g} / \mathrm{kWh}$. With a MT, the ICE rotational speed is constrained by the travelling speed of the vehicle and by the gear ratio of the selected gear.

Figure 4 shows the IFCs both for the MT and the HCVT for the NEDC.

The 5 gear ratios of the MT of this specific car have been optimised for urban driving considering the NEDC specifications. Therefore, the main energy savings are for the urban drive and during the accelerations where the MT forces the ICE to rotate with a speed for which the efficiency is not the highest (for that power). The gear ratios seem not to be optimised for reducing the consumptions for extra-urban driving.

\section{RESULTS AND DISCUSSION}

The procedure previously described was systematically applied to different driving cycles New European Driving Cycle (NEDC) [7], Urban Dynamometer Driving Schedule (UDDS) [19], Urban Dynamometer Driving Schedule for Heavy-Duty vehicles (HUDDS) [19], New 

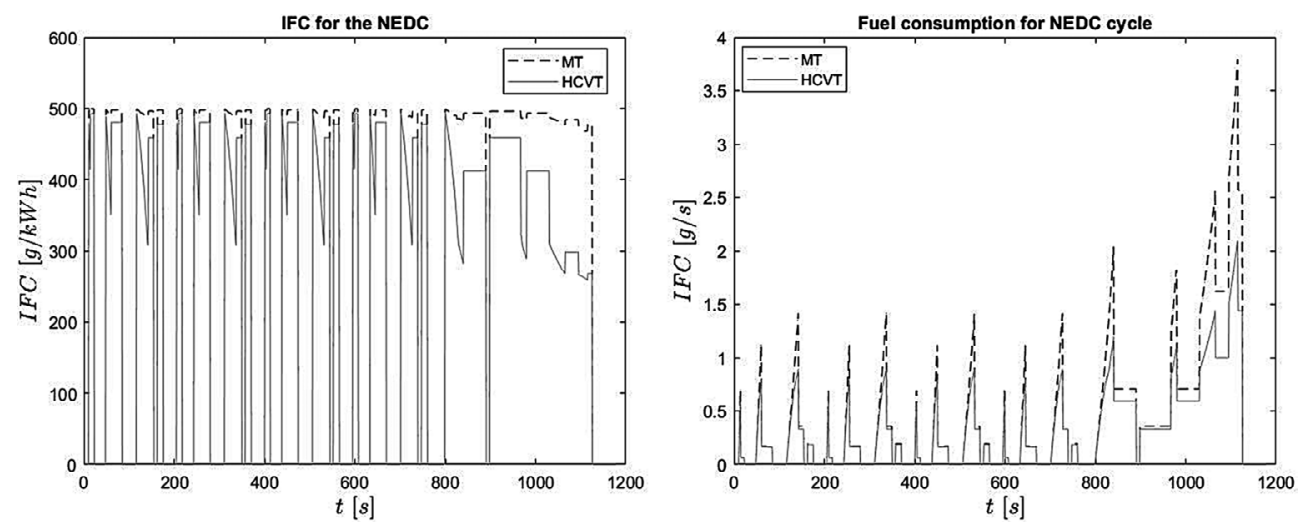

Figure 4: IFCs both for the MT and the HCVT (NEDC).

Table 2: Characteristics of the considered driving cycles.

\begin{tabular}{llllllll}
\hline & NEDC & UDDS & HUDDS & $\begin{array}{l}\text { EPA } \\
\text { NYCC }\end{array}$ & $\begin{array}{l}\text { FTP-75- } \\
\text { sc03 }\end{array}$ & $\begin{array}{l}\text { FTP-75- } \\
\text { sc06 }\end{array}$ & WLTC \\
\hline Distance [m] & 11,023 & 11,996 & 8932 & 1890 & 5765 & 12,893 & 8091 \\
Duration [s] & 1180 & 1369 & 1060 & 598 & 596 & 596 & 122 \\
Avg. speed [km/h] & 33.6 & 31.5 & 30.4 & 11.4 & 34.8 & 79.6 & 28.5 \\
\hline
\end{tabular}

Table 3: Averaged fuel consumptions.

\begin{tabular}{lllllllll}
\hline & & NEDC & UDDS & HUDDS & $\begin{array}{l}\text { EPA } \\
\text { NYCC }\end{array}$ & $\begin{array}{l}\text { FTP-75- } \\
\text { sc03 }\end{array}$ & $\begin{array}{l}\text { FTP- } \\
75-s c 06\end{array}$ & WLTC \\
\hline MT & {$[\mathrm{g} / \mathrm{kWh}]$} & 298.3 & 295.3 & 246.2 & 199.3 & 292.4 & 346.4 & 278.8 \\
& {$[\mathrm{~g} / \mathrm{s}]$} & 0.436 & 0.166 & 0.162 & 0.080 & 0.196 & 0.573 & 0.160 \\
\multirow{3}{*}{ HCVT } & {$[\mathrm{g} / \mathrm{kWh}]$} & 252.9 & 277.4 & 228.6 & 190.3 & 270.8 & 280.6 & 261.7 \\
& {$[\mathrm{~g} / \mathrm{s}]$} & 0.314 & 0.150 & 0.142 & 0.072 & 0.170 & 0.423 & 0.146 \\
\multirow{2}{*}{ Saving } & $\%$ & 28.0 & 9.9 & 11.8 & 10.4 & 13.1 & 26.1 & 8.9 \\
\hline
\end{tabular}

York City Cycle (EPA NYCC) [20], Federal Test Procedure (FTP-75-sc03 and FTP-75-us06) [21] and Worldwide Harmonised Light vehicles Test Cycle (WLTC) [22] (Table 2).

Table 3 summarises the averaged fuel consumptions for the different driving cycles both for the MT and for the HCVT.

Fuel economy is estimated with respect to the instantaneous consumption. The problem is solved numerically with a discretisation time of $1 \mathrm{~s}$. For a given instantaneous power request $P_{R}(t)$ and an imposed ICE rotational speed (function of the travelling speed $v(t)$ and the selected gear), the instantaneous consumption of the MT transmission $I F C_{M T}(t)$ is calculated based on figure 3 . The ideal consumption $\operatorname{IFC}_{H C V T}(t)$ for the same instantaneous power request $P_{R}(t)$ is the lowest value the $P_{R}(t)$-iso-power line crosses (figure 3 ). It is possible to notice that, as expected, fuel consumptions in real driving conditions (represented by dotted lines) is higher than that in ideal driving conditions (figure 5). 

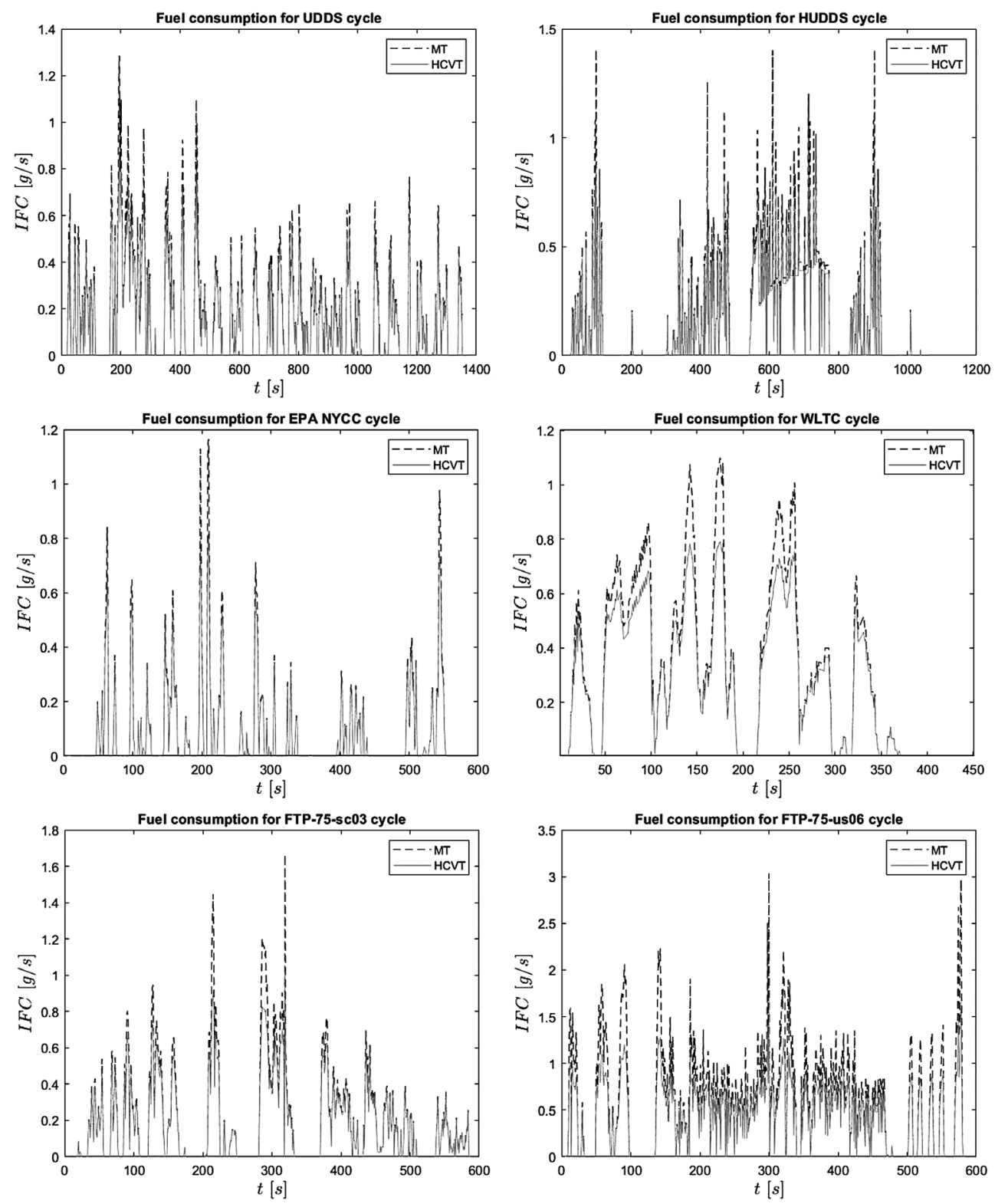

Figure 5: IFCs both for the MT and the HCVT for different cycles.

Finally, the instantaneous fuel consumptions were summed for all the time steps and divided by the driving time to obtain the averaged consumption (table 3 ).

In some cases, the discrepancy is more emphasised (up to 25-30\%) whereas few typologies do not match a significant potentiality of reduction $(<10 \%)$. It is however recognisable a common tendency that rules the deviation in fuel consumption.

It can be noticed that fuel consumption peaks usually occur when the vehicle is accelerating. The continuous variable gear ratio offered by a HCVT, especially in acceleration phases, 
allows maintaining the ICE rotational speed within the optimal range where the efficiency is the highest (for that power).

A bizarre evidence was to obtain a high reduction of the consumption for the NEDC (28\%). This is mainly due to the extra-urban part (right part) of the cycle corresponding to the high speeds (the selected vehicle is still a city car - the 5th gear ratio is probably optimised for the maximum power rather than for the fuel efficiency). Moreover, this result mirrors a sharp criticism: popular opinions often report the inadequacy of NEDC to represent real driving conditions. This might justify the excellent saving potential.

Another cycle that shows a good saving potential is the us06 supplementary FTP-75 cycle. As for the NEDC cycle, the FTP-75-us06 is an extra-urban driving cycle for witch the selected car is not designed for. Driving cycles characterised by low speed where the absorbed power is generally lower, show lower saving percentages. Nevertheless, a reduction of the fuel consumption around $10 \%$ could represent a significant improvement of the actual state of the art.

\section{FUTURE WORKS}

Based on the findings of this preliminary research, considering the high saving potentials, a HCVT transmission is under development.

\section{CONCLUSIONS}

The consumption of a city-car equipped with a MT was evaluated on different driving cycles. With the hypothesis of neglecting the gearbox power losses, the consumption on the same driving cycles was calculated imagining having the optimal gear ratio.

The comparison has shown big potentials for reducing the fuel consumptions acting on the ICE working point, especially for extra-urban cycles. Even if at low speed the fuel savings result reduced, a reduction up to $10 \%$ seems to be possible on each driving cycle.

\section{REFERENCES}

[1] Tianze ShiFuquan ZhaoHan HaoZongwei Liu, "Development Trends of Transmissions for Hybrid Electric Vehicles Using an Optimized Energy Management Strategy," Automot. Innov., vol. 1, no. 4, pp. 291-299, 2018.

[2] J. Ruan, Q. Song, and W. Yang, "The application of hybrid energy storage system with electrified continuously variable transmission in battery electric vehicle," Energy, vol. 183, pp. 315-330, 2019.

[3] N. H. Truong, "The research and calculation for the selection of motor and battery for five seat passenger car when replacing engine by an electric motor," Lect. Notes Networks Syst., vol. 104, pp. 710-719, 2020.

[4] F. Van Der Sluis, L. Romers, G.-J. Van Spijk, and I. Hupkes, "CVT, Promising Solutions for Electrification," SAE Tech. Pap., vol. 2019-June, no. June, 2019.

[5] M. Yao, D. Qin, X. Zhou, S. Zhan, and Y. Zeng, "Integrated optimal control of transmission ratio and power split ratio for a CVT-based plug-in hybrid electric vehicle," Mech. Mach. Theory, vol. 136, pp. 52-71, 2019.

[6] F. Bottiglione and G. Mantriota, "Power Flows and Efficiency of Output Compound e-CVT," Int. J. Veh. Technol., vol. 2015, 2015.

[7] "E/ECE/TRANS/505/Rev.2/Add.100/Rev.3."

[8] Stephen E. Plotkin, "Examining Fuel Economy and Carbon Standards for Light Vehicles. Discussion Paper No. 2007-1," JTRC, 2007.

[9] C. of the E. Communities, "Regulation (EEC) no 4064/89 merger procedure," 1999. 
[10] "www.fiat.com."

[11] "www.fcagroup.com."

[12] C. Budinger, M., Hazyuk, I., Coic, Multi-Physics Modeling of Technological Systems. 2019.

[13] F. Concli et al., "Load independent power losses of ordinary gears: Numerical and experimental analysis," in 5th World Tribology Congress, WTC 2013, 2013, vol. 2.

[14] F. Concli, "Thermal and efficiency characterization of a low-backlash planetary gearbox: An integrated numerical-analytical prediction model and its experimental validation," Proc. Inst. Mech. Eng. Part J J. Eng. Tribol., vol. 230, no. 8, 2016.

[15] F. Concli and C. Gorla, "Analysis of the oil squeezing power losses of a spur gear pair by mean of CFD simulations," in ASME 2012 11th Biennial Conference on Engineering Systems Design and Analysis, ESDA 2012, 2012, vol. 2.

[16] G. C. Concli F., "Influence of lubricant temperature, lubricant level and rotational speed on the churning power loss in an industrial planetary speed reducer: computational and experimental study," Int. J. Comput. Methods Exp. Meas., vol. 1, no. 4, pp. 353-366, 2013.

[17] F. Concli, "Low-loss gears precision planetary gearboxes: reduction of the load dependent power losses and efficiency estimation through a hybrid analytical-numerical optimization tool," Forsch. im Ingenieurwesen/Engineering Res., 2017.

[18] F. Concli and C. Gorla, "CFD simulation of power losses and lubricant flows in gearboxes," in American Gear Manufacturers Association Fall Technical Meeting 2017, 2017, vol. 2017-Janua.

[19] United States Environmental Protection Agency, "Vehicle and Fuel Emissions Testing."

[20] "The US EPA NYCC test was developed for chassis dynamometer testing of light-duty vehicles," CFR, vol. 40, no. 86.

[21] U. E. P. Agency, “EPA Federal Test Procedure FTP-75.” 2008.

[22] Vehicle Certification Agency, "Worldwide Harmonised Light vehicles Test Cycle." 